\title{
E-learning: Developing Tomorrow's Education
}

\author{
Rohit \\ Faculty of Engineering \\ Rezekne Academy of Technologies \\ Rezekne, Latvia \\ rohitpruthi55@gmail.com
}

\author{
Peter Grabusts \\ Faculty of Engineering \\ Rezekne Academy of Technologies \\ Rezekne, Latvia \\ peteris.grabusts@rta.lv
}

\author{
Artis Teilans \\ Faculty of Engineering \\ Rezekne Academy of Technologies \\ Rezekne, Latvia \\ artis.teilans@rta.lv
}

\begin{abstract}
E-learning refers to the term to deliver education or training using digital resources. Computerbased learning, which is considered the keystone of today's E-learning concept, was born in the 80s. Earlier E-learning provides education using only text as with the development in technology it allows adding various forms, i.e., Graphical Text, Images, Video Conferencing etc. In today's time, the concept of is E-learning growing at a rapid pace. Improved bandwidth and growing technology helped in pushing the expansion of E-learning. Along with the university, large corporate companies are also resorting to E-learning. Elearning provides many advantages as compare to Instructor-led training (ILT). E-learning saves the times of travel as physical presence is not required. Education can be provided from anywhere at any time. E-learning is costeffective also as the course, once developed, can be modified easily. There can some concern which can be faced by the trainer and leaners in future. Adopting E-learning will be a step towards saving the environment. It will be environmentally friendly as tablets will replace books; paper notes will be replaced with digital messages. Digital tools will help to reduce the burden of a student. Artificial Intelligence is a prevalent concept in computer science. A branch of AI, known as a Neural Network, is based on the human brain. The research's main aim is to review existing methods and analyse further possibilities of E-learning systems with neural networks.
\end{abstract}

Keywords - E-learning, education, E-learning limitations, new technologies, Artificial Intelligence, Neural Network

\section{INTRODUCTION}

Education is an essential element of life in today's time. Any obstacle during education affects the interaction between a teacher and student to some extent. Obstacles can come in any way and can come in any way, such as deteriorating health or being unable to provide timely training, lack of teachers, or lack of teaching resources such as textbooks. These problems can be overcome using digital resources involving various methods, computerbased operation network, computer-assisted instruction, audio conferencing and video conferencing, internet worldwide websites and a systematized feedback system (see Fig. 1). It is not related to only training and teaching but also about learning tailored to individuals.

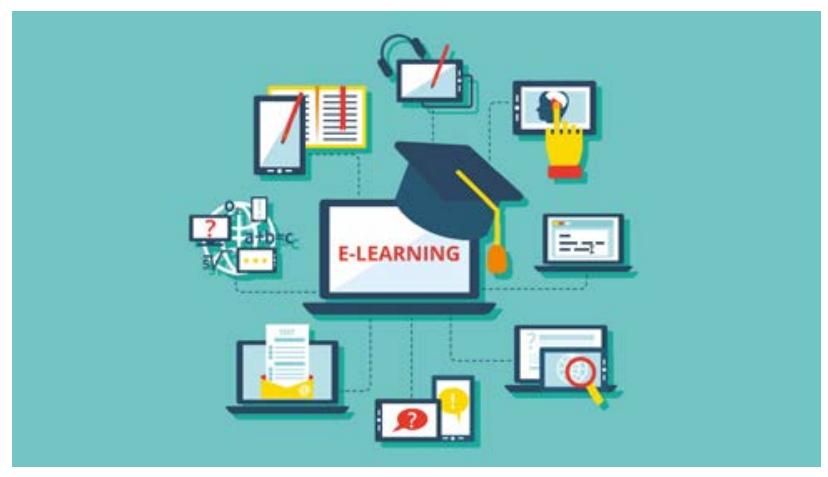

Fig. 1. Structure of E-learning (Source: servicedesignblog.com).

E-learning makes the process of delivering education by removing the necessities of the physical presence. Ever since the internet has been used to provide education, the quality of education has increased a lot [1]. It boosts the study process by offering various ways of giving education [2]. Using E-learning, students of any age and abilities have the chance to learn anywhere, at any time and in their place. A single definition of E-learning has not been found yet. Terms that are commonly used to define E-learning include online learning, networked learning, distributed learning, virtual learning, internet learning, web-based learning, and distance learning [3]. E-learning delivers content via Internet, Intranet and Extranet.

\section{TYPES OF E-LEARNING}

Fundamentally, there are two types of E-learning [4].

Synchronous E-learning. 
This type of E-learning is known as real-time learning also. In this type of e-learning, the teacher and learner are online at the same time and interact from different places (See Fig. 2).

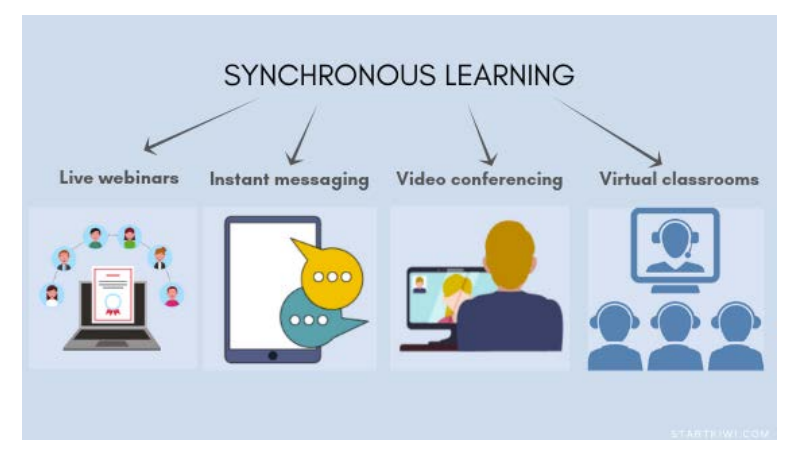

Fig. 2. Synchronous Learning (Source: Startkiwi.com).

They communicate via video conference, audio conference, chat. In this type of learning, sharing and ideas can be done during the session-this type of e-learning gaining popularity because of improved internet bandwidth capabilities. This type of E-learning delivers content two ways or more at the same time. Activities that are used in this type of learnings are:

- Chat and IM.

- Video Conference.

- Audio Conference.

- Live webcasting.

- Application sharing.

- Polling.

\section{Asynchronous E-learning.}

It is also known as a pause-and-resume kind of learning. In this type of e-learning, the teacher and students are not online at the same time. It's also known as self-paced learning (See Fig. 3). In this, learners can learn at any time, download eBook's forums, CDs, DVDs etc.

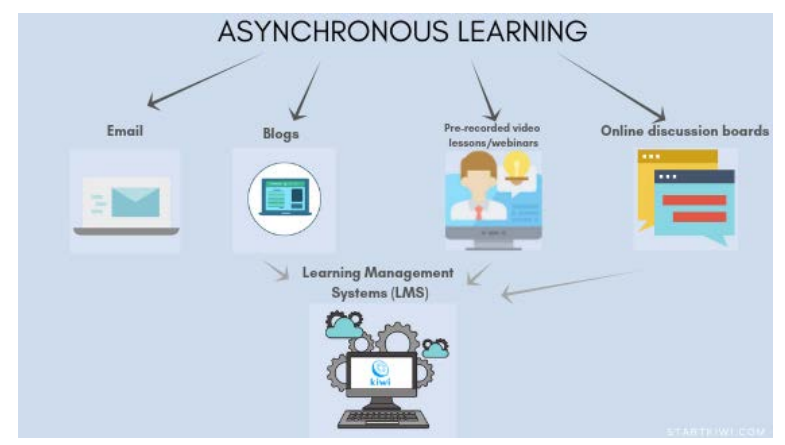

Fig. 3. Asynchronous Learning (Source: Startkiwi.com).

This type of E-learning delivers content in one way at one point in time [4]. This type of E-learning is gaining more popularity than synchronous because learners can learn at their preferable time, not by affecting their daily routines.

Activities used in asynchronous learning are:

- Email.

- Discussion forum.

- Personal or Public blog.

- Webcasting.

- CD-ROMs.

- Broadcast television that delivers learning contents

In this learning, audio and video sessions can be recorded during the lecture and made available for the learners who cannot attend the live event.

\section{CATEGORY OF E-LEARNING}

These are considered as follow:

\section{1) Courses}

Most discussion on E-learning focuses on educational courses. Education courses are added with different media or modified to a network for online access for a learner. Some learning management systems are top-rated today, such as TalentLMS, LearnDash and SkyPerp, which education institutes commonly use. The designer has begun to add innovative components in courses such as storytelling and simulations into the material to achieve more motivational courseware.

\section{2) Informal learning}

Learning from self-directed learning or learning from their own experience is mainly known as Information learning. Sometimes for the need for information drivers our search [5]. Search engines (Google, Bing) connected with some storage tools or personal knowledge management like blogs or wikis present a powerful toolset in knowledge.

\section{3) Blended learning}

This learning is a combination of a face to face and online learning. It combines several different delivery methods as web-based courses and computer communication practices with face-to-face instruction. Blended learning utilizes the best of classrooms with the best of online knowledge [6].

\section{4) Knowledge management}

E-learning has the potential to improve the learning opportunities to a much larger audience as compared to standard face to face training session. Usually, knowledge management creates an atmosphere between people to share knowledge on distribution, adoption, and information exchange [7].

\section{5) Learning network}

A learning network is a procedure for developing and preserving the relationship between learners [8]. The reason learning networks are enhancing is it offers to exchange with expertise, engage with other learners.

\section{E-LEARNING TOOLS}

1) Curriculum tools 
These tools are widely used in today's time while providing education in school or universities (See Fig. 4).

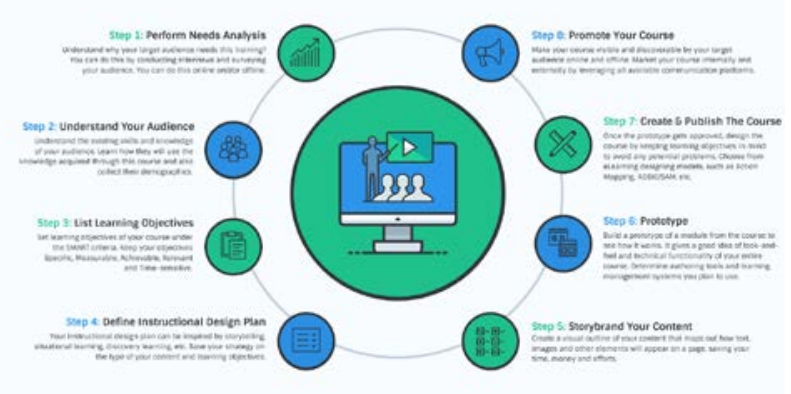

Fig. 4. Graphical Representation of Curriculum Tools (Source: venngage.com).

Curriculum tools are included with three tools:

a) Instruction tools

This tool includes curriculum design, online quizzes.

b) Administration tools

These tools include authorization, administration, and file management.

c) Student tools

Explore study material, Sharing, self-testing and evaluation.

\section{2) Digital library tool}

This tool helps the learner to find the correct information from a vast amount of digital material. It includes discovering a unique collection or searching among the enormous digital database (see Fig. 5) [3].

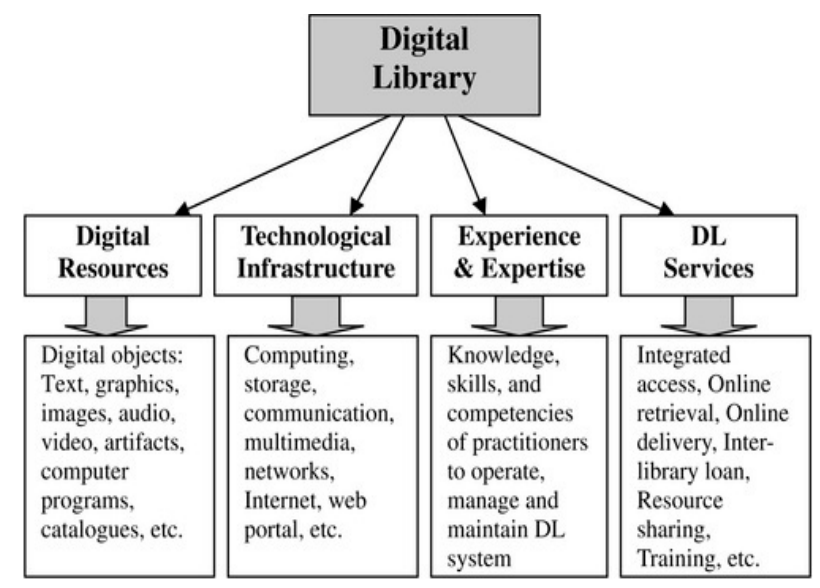

Fig. 5. Digital Library (Source:IndiaMart.com)

\section{BENEFITS OF E-LEARNING}

Reduced costs- E-learning is cost-effective compared to face to face (f2f) traditional method-few significant benefits of E-learning over f2f learning [9].
Quick delivery of Lesson - Compared to the traditional classroom method, E-learning provides the lesson's fast delivery. Reasons how E-learning helps to save time:

- It saves times of travel. The lesson can be acquired at own place with a high level of comfort.

- The learner can focus on the area of interest instead of focusing on each area. They can skip the area which is out of curiosity.

- To some extent, obstacles arising from nature cannot affect the process of E-learning.

Vast audience - In traditional classroom learning, learners' gathering is limited due to limited sitting space. With E-learning number of learners can be increased as compared to f2f education. The number of learners cannot be unlimited due to application limits, but it is still very much compared to the f2f method.

Lectures can be taken numbers of time-Because digital media and resource gave, the lecture can be stored on clouds or local storage. These lectures can help learner for revising the content or preparing for the exam [8].

Environment friendly - E-learning is paperless learning. It helps to save the environment to some extent. In a study, it has been found that E-learning generated 85\% less amount of $\mathrm{CO} 2$ as compared to campus-based learning. E-learning is highly eco-friendly as there is no need to cut trees for papers [9].

24/7 Access to Learning - Using E-learning, the learner is free to study accordingly to their plans. Lerner can build their schedule based on their most productive hours.

\section{ARTIFICIAL INTELLIGENCE AND E-LEARNING}

Technology is growing at a very rapid speed in today's time. In a way, everything is shifting to the digital world, but the ordinary programming language still can't deal with qualitative information. With the power of computer science, computers can decide for themselves. The term "Artificial Intelligence" (AI) was coined by John McCarthy in 1956 [10]. It can be defined as holding multiple ideas in mind simultaneously and still retain the ability to function (see Fig. 6). AI is programmed to work with its developed programming language to manipulate knowledge more effectively. AI's scientific goal is to understand intelligence by building computer programs that exhibit intelligent behaviour using symbolic inference or reasoning inside the machine. The two central attempts to make computer ability to think intelligent are game playing and theorem proving. There are six branches of AI (see Fig. 6). 


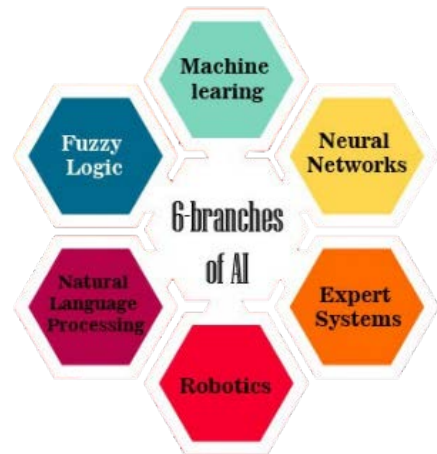

Fig. 6. Components of AI

In this paper, the authors mainly discuss the implementation of Neural networks (NN) with E-learning.

Neural Network - It is a network that works similar to the tasks performed by neuron of humans. Neural. The structure of the human brain inspires this network to help the computer more like a human.

Working of Neural Network - NN adapt itself during the training period. After sufficient training, NN can relate input to outputs and solve a solution to the problem (see Fig. 7).

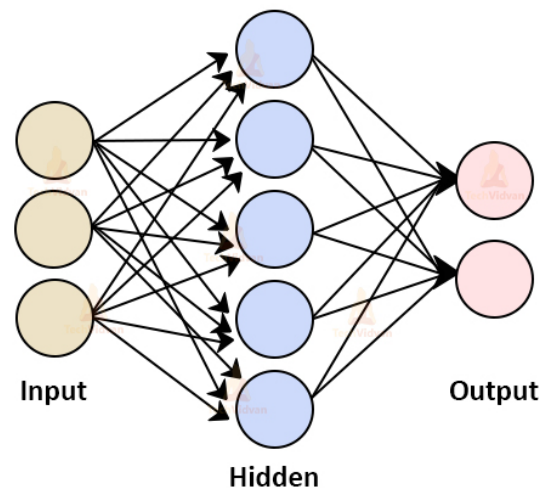

Fig. 7. Neural Network Architecture (Source: upgrad.com)

In NN, all layers are connected. Mainly two layers The input and output are layers visible to the external world. Input layers take information and process according to the neuron's hidden layer and activation after getting the specific weights. In the end, it generates to provide the solution to the output layer. The main computation of NN takes place in between hidden layers [11].

Algorithm of $\mathrm{NN}$ -

Training dataset - in this sample of data process to input layer to train the $\mathrm{NN}$.

Validation dataset - in this dataset is used for tuning the performance of NN.

Test dataset - the dataset is used to check the accuracy of the neural network.

Neural Network can be implemented in different approaches in E-learning. In this paper, the authors discuss a one-way communication approach. The system authors trying to develop using a neural network will communicate in one way with the learner.

One way communication approach - In this approach, the dataset used to train the $\mathrm{NN}$ will be based on the preliminary information from the individual learner as per their goal, achievement, area of interest and motivation; after training, NN will design the course for individually for the learner. Facial expression is one of the essential features of human emotion recognition. The system will capture the emotion of the learner during the ongoing session. To capture the emotion Convolutional neural network (CNN) [12] will be used. The facial expression will help to get the honest feedback of a learner towards the session. These emotions will be used as feedback to design the next session (see Fig. 8)

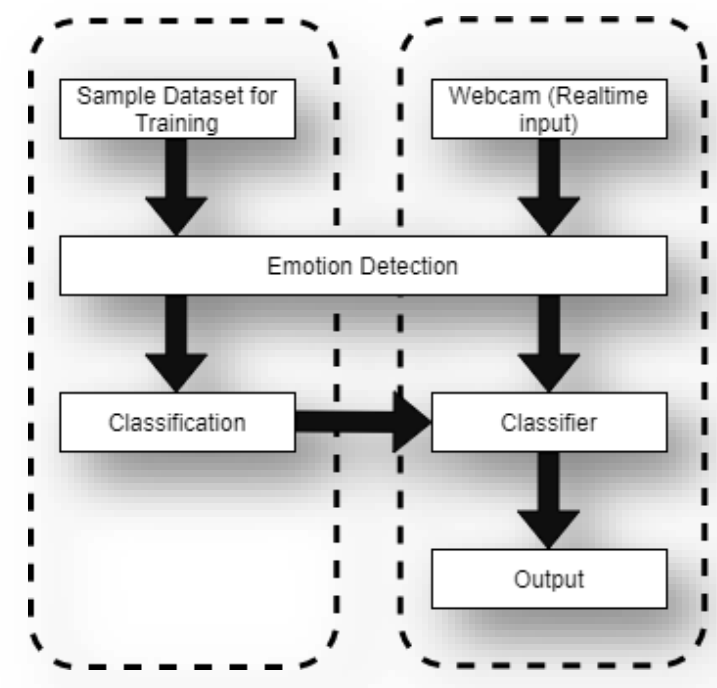

Fig 8. Workflow of the emotion detection model

The emotion model that the author will implement in the system will follow simple steps.

- For training the neural network, it will take a sample dataset.

- After successful training, it will take a real-time image of a learner using a webcam to capture the current emotion.

Using Neural Network with E-learning can prove to be very beneficial in the futures [13].

1. Real-time questioning - NN will work as a Virtual tutor and answer any questions quickly. One most considerable benefit of this will be a student can pause the learning process and ask any question as soon as it pops up in mind [12].

2. Fresh Content - NN is also experimented with generating new and fresh content. In recent time a movie's script name "Sunspring" was developed by NN. NN can be used to create the entire scope of a course. It will reduce the burden of a course designer. 
3. Personalize Learning - With the help of NN, it is also possible that the delivery of content to each student will be very to their goals and previous knowledge. AI can track the previous achievements and deliver the content accordingly.

\section{CONCLUSIONS}

Shifting from standard f2f learning to E-learning will be a huge step. It can be very beneficial in many ways. Moving to E-learning will solve any natural cause that interrupts learning. However, embedding E-learning with regular system process is both complex and far-reaching. As discussed above, AI with E-learning and rapid development will help provide exciting ways for a learner. Students will get rid of papers notes as things will be on clouds, and they can access them anytime. It will be helping to protect the environment. The concept we are developing using the neural network will provides benefits to an institution in various ways, i.e., in financial costs of a course and reduce the workload of employees of an institute. As discussed, CNN will be used to easy to get the current emotion of a learner using an automatic system during the learning process, which will help find the right motivation for each learner.

The authors are developing a fully automated system that will work based on user provided input according to their area of interest and previous knowledge in the field. This system will generate entire course according to the each individual user.In present time system will work only one way direction.

\section{REFERENCES}

[1] J. Morrison, “8 Ways Technology Improves Education,” February 24, 2018. [Online]. Available: 8 Ways Technology Improves Education - eLearning Industry. [Accessed: March 21, 2021].
[2] R. Andrews and C. Haythornthwaite, Introduction to E-learning. Vancouver, 2007.

[3] N. D. Oye, M. Salleh and N.A. Iahad, "E-Learning Methodologies and Tools," International Journal of Advanced Computer Science and Applications, vol. 3, no. 2, 2012.

[4] M. Georgescu, "The Future of E-Learning: Designing Tomorrow's Education," COLLABORATIVE SUPPORT SYSTEMS IN BUSINESS EDUCATION, Babes Bolyai University of Cluj Napoca, 2006. [Online]. Available: The Future of E-Learning: Designing Tomorrow's Education by Mircea Georgescu :: SSRN [Accessed: March 12, 2021].

[5] A. W. Bates, "Distance Education in a Dual Mode Higher Education Institution: A Canadian Case Study, "in Hope, A. and Guiton, P. (eds) Strategies for Sustainable Open and Distance Learning London: Commonwealth of Learning and RoutledgeFalmer Press, 2005.

[6] E. Kaplan-Leierson, "E-learning glossary," 2006. [Online]. Available:

https://www.puw.pl/sites/default/files/content_files/zasob_do_pob rania/355/elearn-gloss-learncircuits.pdf [Accessed: March 12, 2021].

[7] L. R. Bruce and P.J. Sleeman, Instructional Design: a Primer, Greenwich: Information Age Publishing, 2000.

[8] S. R. Hiltz and M. Turoff, "What makes learning networks ?," Communications of the ACM (45:5) 2002, pp. 56-59, 2002.

[9] A. P. Chitra and M. A. Raj, "E-Learning," Journal of Applied and Advanced Research, 2018: 3, p. S12, 2018.

[10] G. Singh, A. Mishra and D. Sagar, "An overview of artificial intelligence," SBIT journal of sciences and technology, vol. 2, no. $1,2013$.

[11] upGrad, "Neural Network: Architecture, Components \& Top Algorithms,” 6 May, 2020. [Online]. Available: https://www.upgrad.com/blog/neural-network-architecturecomponents-algorithms/ [Accessed: March 21, 2021].

[12] IBM Cloud education, “Convolutional Neural Networks," 20 $\begin{array}{lll}\text { October } 2020 . & \text { [Online]. }\end{array}$ https://www.ibm.com/cloud/learn/convolutional-neural-networks. [Accessed: March 21, 2021].

[13] N. Neelakandan, “Artificial-intelligence-based-platform-impactfuture-elearning,” 6 October 2019. [Online]. Available: https://elearningindustry.com/artificial-intelligence-basedplatform-impact-future-elearning.

[Accessed: March 21, 2021]. 